\title{
Cutaneous Horn of the Neck with Atypical Etiology: Is this Disease Genetically Predisposed?
}

\author{
Sunil Garg*, Amit Prakash, Deepika Sethi, Achal Gulati and Renu Gupta \\ BSA Medical College, India
}

Submission: August 18, 2017; Published: August 28, 2017

*Corresponding author: Sunil Garg, BSA Medical College, Sector 6, Rohini, Delhi, India, Tel: 7838840004; Email: dr.sunilgarg07@gmail.com

\begin{abstract}
Cutaneous horn is a proectile, conical, dense, hyperkeratotic nodule that resembles the horn of an animal. It may arise from any part of body. Its presence is quite rare and most commonly found in the regions of the body mostly exposed to sunlight like scalp, forehead, eyelids, ear, nose, lips and upper extremities. Association with seborrheic keratosis is very common. Very rarely it may be found on hidden areas of the body like penis or neck. Various benign, pre-malignant, and malignant cutaneous diseases have been described as underlying factors for its occurrence. Trauma has also been described as a very rare causative factor in the etiology of cutaneous horn. We are hereby presenting such a rare case of cutaneous horn presenting in the neck region which the patient usually used to remain covered owing to his habit, with the history of trivial fingernail trauma which rapidly progressed to cutaneous horn in four months, suspecting a genetic predisposition for its occurrence. Interestingly there was no underlying pathology found in this case.
\end{abstract}

Keywords: Cutaneous horn; Genetic predisposition; Neck; Trauma

\section{Introduction}

Cutaneous hornas the name suggests is a horn like projection arising from skin which is a dense, hyperkeratotic, yellow-white nodule. The diagnosis of cutaneous horn is made only on the basis of its appearance. True pathology may be different in every individual case which had triggered the formation of horn. The lesion underneath may be benign, premalignant or malignant. This underlying diagnosis is made by excision biopsy of the horn and the final treatment is based on this diagnosis. Various large studies have shown variable percentages of benign or premalignant or malignant conditions [1-3]. Study by Mantese et al found a benign pathology like viral wart, keratotic acanthoma, keratosis seborrhoeica, benign epithelial hyperplasia etc. in $41 \%$ cases [3]. $51 \%$ of the lesions were premalignant and $7 \%$ were malignant in his case series. As an etiological factor, trauma has not found any place in most of large case studies. However, isolated case repots have mentioned it as an etiological factor in the formation of horn [4]. Radiation, chronic irritation, and even human papillomavirus infection [5] may also be the precipitating factors for horn causation.

Cutaneous horn is mostly present on sun exposed areas like scalp and upper limb which lead to the development of actinic keratosis, solar keratosis succeeding thereafter to the formation of horn. Hidden areas are rarely found to harbor the horn like chest, penis or gluteal region [6]. We are hereby presenting such a rare case of cutaneous horn presenting in the lower part of his neck which is hidden by virtue of its location as well as the habit of the patient who usually used to keep it covered by a cloth. The history of trivial fingernail trauma was present only four month back which rapidly progressed to cutaneous horn. To the best of our knowledge this is a very rare etiological factor for the formation of horn.

\section{Case Report}

A 50 year old male farmer presented in ENT OPD at our tertiary care center with complaint of single horny projection of the lower part of right side lateral neck near clavicle since four months. Apart from itching the patient had no history of pain or discharge from site of the lesion. The meticulous history taking revealed an incidence of fingernail trauma at the site of the lesion four months back. The patient told that on healing, the area got hardened, and then it slowly developed into a small hard skin outgrowth. The lesion kept on increasing in size during these four months to reach the present size as shown in picture (Figure 1). Patient was a chronic smoker and history of hypertension was present. Rest of the history was normal. Physical examination showed a keratotic, irregular shaped crust with a pedicle on right lateral lower neck. Other ENT examination was unremarkable. There was no regional lymphadenopathy. Rest of the general examination revealed no abnormality. All 


\section{Global Journal of Otolaryngology}

routine investigations which included complete blood count, chest X-Ray, urine examination etc were normal.

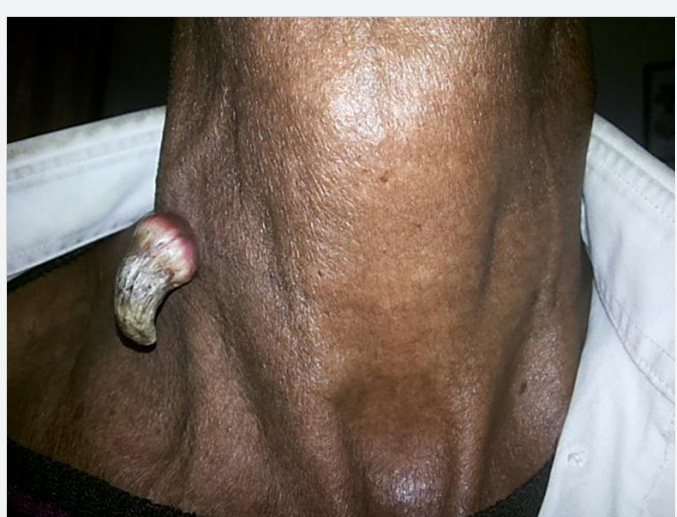

Figure 1: Dark skinned patient with cutaneous horn of lower part of neck.

A diagnosis of cutaneous horn was made on clinical basis Excision biopsy was planned to rule out underlying pathology. Excision was done under local anesthesia using radiofrequency probe. The specimen was sent for histopathological examination. On histopathological examination, the concentric layers of cornified epithelial cells were present. Histopathology revealed marked hyperkeratosis and hyperplasia of squamous epithelium consistent with cutaneous horn (Figure 2). There was no evidence of any other pathology underneath which was surprising for us. No evidence of malignancy was noted. The patient is on follow-up since last one year with no untoward complication or recurrence to report till date.

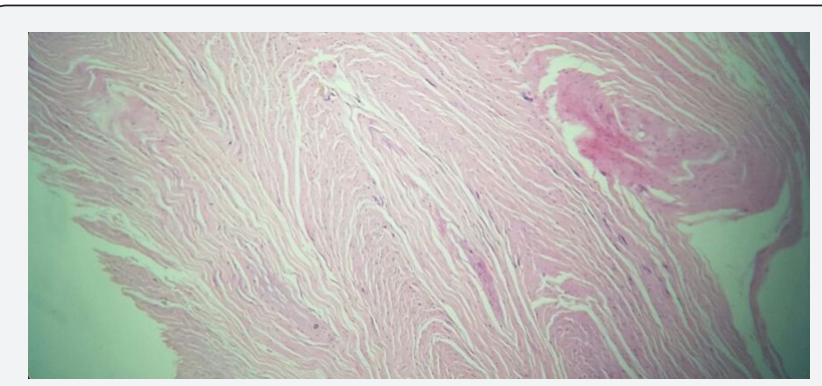

Figure 2: Photomicrograph showing diffuse hyperkeratosis and parakeratosis consistent with cutaneous horn.

\section{Discussion}

Cutaneous horns are rare skin lesions caused by overgrowth of the most superficial layer of skin. Occurrence of the cutaneous horn is seen in people 50 years or older and with no sex predilection. Present case was of the age of 50 years. The distribution of the cutaneous horn is usually in sun-exposed areas, particularly the face, pinna, nose, forearms and dorsum of the hands. Our case presented over the lower part of the neck. They grow slowly over years to decades. Sometimes rapid growth may occur which is what exactly has happened in the present case. Mostly they are solitary. They are variable in shape, size and colour. Most have a yellow-white colour. They are thought to result from underlying benign, premalignant or malignant pathology, in $61.1 \%, 23.2 \%$ and $15.7 \%$ of cases respectively [1].

Cutaneous horn has been commonly seen in light skinned people with exposure to sunlight acting as trigger [3]. It is prudent to note that the present patient was a dark skinned person. The neck because of its exposed location is particularly liable to the deleterious effects of ultra violet rays of sunlight and therefore a potential site for formation of this lesion. However in the present case the lesion was in the lower part of the neck which is less likely to be exposed to sun rays and also the patient used to wear a cloth around the neck called "gamcha" in slang language. Other risk factors like viral wart, keratotic acanthoma, keratosis seborrhoeica, solar keratosis or squamous cell carcinoma etc. were not present in our case. Though, history of fingernail trauma seems to have been the only causative factor in this case.

Aetiology of cutaneous horn is still not known clearly till date. However underlying pathology has been highlighted by all the authors $[1,3]$. The factors which trigger the keratinocytes to proliferate are not well understood till date. The occurrence of benign or malignant lesions and their relationship with time duration goes well with the routine causation of these benign/ malignant lesions when there is no formation of cutaneous horn. One unique and important point to note here is that in cases where trauma has been described as a predisposing factor in horn formation it is present mostly in hidden areas of the body not exposed to sunlight.

These traumatic horns may be representing separate pathophysiologic mechanism in its causation. In most large case studies, trauma has never been defined as an unblemished factor in the etiology of cutaneous horn. Are people genetically predisposed to the formation of cutaneous horn? Nowhere in the present English medical literature has genetic factor ever been explored before. Presence of small number of cases of cutaneous horn has contributed to sparse literature on this etiological factor. A trivial trauma like this causing formation of horn seems unlikely until some other factor is contributing. Any relation to genetic alteration may be contributing towards their causation. Future studies may through some light on this important aspect of aetiology.

Excision biopsy of the lesion including base and histopathological examination to rule out malignancy is mandatory. Complete removal of the horn with curettage down to normal tissue gives a satisfactory result still there may be a recurrence. A careful physical examination of the lymph nodes draining the area of lesion is mandatory. Invasive squamous cell carcinomais most likely present in male patients with advanced age and a lesion which has a height less than the diameter of the base; does not have terrace formation; displays base erythema; and painful [7]. If malignancy is present then it should be excised 
with appropriate margins and evaluation for metastasis is done. Excision may be done using electrocautery, cryotherapy, and carbon dioxide or Nd-YAG laser.

The present case is being highlighted due to the rarity of the lesion at this site with occurrence of the lesion after such a trivial trauma which raised the doubt of role of genetic factors in its acquisition. There was no other underlying pathology found on histopathology. This is the first case reported to have been excised using radiofrequency.

\section{Declaration of the Conflicting Interests}

The authors declared no potential conflicts of interest with respect to and/or publication of the article.

\section{Funding}

Authors received no financial support for the research, authorship and/or publication of the article.

\section{Ethical Approval}

Consent was taken from parents of the children for surgery and publication of the case report.

\section{References}

1. Yu RC, Pryce DW, Macfarlane AW, StewartTW (1991) A histopathological study of 643 cutaneous horns. Br J Dermatol 124: 449-452.

2. Schover RH, Hodge SJ, Gaba CR, Owen LG (1979) Cutaneoushorns: a histopathological study. South Med J 72: 1129-1131.

3. Mantese SA, Diogo PM, Rocha A, Berbert AL, Ferreira AK, et al. (2010) Cutaneous horn: a retrospective histopathological study of 222 cases. An Bras Dermatol 85(2): 157-163.

4. Purohit GN, Agarwal N, Agarwal R (2007) Cutaneous Horn Following Injury to Pinna. Indian J Otolaryngol Head Neck Surg 63(Suppl 1): S47-S48.

5. Solvian GA, Smith KJ, James WD (1990) Cutaneous horn of the penis: its association with squamous cell carcinoma and HPV-16 infections. J Am Acad Dermatology 23: 969-972.

6. Pattabi S, Kumar GG, Bharathi CDK (2015) Multiple Sebaceous Horn on the Penis- an Interesting Case Report. Indian J Surg 77(Suppl 2): S724-S725.

7. Pyne J, Sapkota D, Wong JC (2013) Cutaneous horns: clues to invasive squamous cell carcinoma being present in the horn base. Dermatol Pract Concept 3(2): 2.

\begin{tabular}{|l|}
\hline \multicolumn{1}{|c|}{ Your next submission with Juniper Publishers } \\
- Quality Editorial service \\
- Swift Peer Review \\
- Reprints availability \\
- E-prints Service \\
- Manuscript Podcast for convenient understanding \\
- Global attainment for your research \\
- Manuscript accessibility in different formats \\
( Pdf, E-pub, Full Text, Audio) \\
- Unceasing customer service \\
Track the below URL for one-step submission \\
https://juniperpublishers.com/online-submission.php \\
\hline
\end{tabular}

